THU0513

\section{IS THERE A ROLE OF SERUM NESFATIN-1 LEVEL IN} FIBROMYALGIA?

B. Bilgici ${ }^{1}$, Y. Akyol ${ }^{2}$, Y. Ulus ${ }^{2}$, S.S. Urkmez ${ }^{1}$, O. Kuru ${ }^{2} .{ }^{1}$ Biochemistry; ${ }^{2}$ Physical Therapy and Rehabilitation, Ondokuzmayıs university, Samsun, Turkey

Background: Fibromyalgia (FM) is characterised by chronic widespread pain, sleep disturbances, affective disorders, fatigue, cognitive dysfunction, anxiety and depressive episodes and its pathogenesis is still unclear. ${ }^{1}$ Nesfatin-1 is a recently identified anorexigenic hypothalamic polypeptide which plays role on mood, stress, sleep, anxiety, eating behaviour, and metabolic regulation. ${ }^{2,3}$ Serum level of nesfatin-1 may be associated with the physiopathology and clinical semptoms of FM.

Objectives: The aim of the present study was to compare serum nesfatin- 1 level in patients with FM with healthy controls, and to investigate its relationship with demographic features and clinical parameters such as pain severity, disease activity, fatigue, emotional status, and sleep quality in FM patients.

Methods: Forty-six female patients with FM and 46 healthy female controls were included in the study. Demographic characteristics of participants were recorded. Severity of Pain by Visual Analogue Scale (VAS), disase activity by Fibromyalgia Impact Questionnaire (FIQ) were evaluated in patients with FM. Fatigue by Multidimensional Assesment of Fatigue (MAF), sleep quality by Pittsburgh Sleep Quality Index (PSQI), emotional status by Beck Depression Inventory (BDI) and Beck Anxiety Inventory (BAI) were performed in both groups. Serum nesfatin-1 concentrations were measured in all participants.

Results: Serum nesfatin-1 concentrations were significantly low in patients with FM compared to the healthy subjects $(p<0.05)$. When compared to the FM patients without anxiety, serum nesfatin-1 concentrations were significantly increased in FM patients with anxiety $(p<0.05)$. Serum nesfatin- 1 concentrations were positive correlated with BAI scores in patients with $\mathrm{FM}(\mathrm{p}<0.05)$ whereas no statistically significant correlations were found between serum nesfatin-1 concentrations and age, BMI, and other clinical parameters in the patient and control group ( $p>0.05)$

Conclusions: According to the results of this study, it can be suggested that decreased nesfatin-1 plays a role in the FM pathogenesis and nesfatin-1 may mediate anxiety-related responses in FM patients.

\section{REFERENCES:}

[1] Talotta R, Bazzichi L, Di Franco M, Casale R, Batticciotto A, Gerardi MC, et al. One year in review 2017: fibromyalgia. Clin Exp Rheumatol 2017;35:6-12.

[2] Oh-I S, Shimizu H, Satoh T, Okada S, Adachi S, Inoue K, et al. Identification of nesfatin-1 as a satiety molecule in the hypothalamus. Nature 2006;443:709-12.

[3] Aydin S. Multi-functional peptide hormone NUCB2/nesfatin-1. Endocrine 2013;44:312-25.

Disclosure of Interest: None declared

DOI: 10.1136/annrheumdis-2018-eular.2467

\section{THU0514 FAT BUT FIT. THE COMBINED ASSOCIATION OF BODY MASS INDEXAND CARDIORESPIRATORY FITNESS WITH THE FIBROMYALGIA SEVERITY AND TENDERNESS: THE AL-ÁNDALUS PROJECT}

P. Acosta-Manzano ${ }^{1}$, B. Gavilán-Carrera ${ }^{1}$, V. Segura-Jiménez ${ }^{2}$, M. Borges-Cosic ${ }^{1}$, I.C. García-Rodríguez ${ }^{1}$, V.A. Aparicio ${ }^{3}$. ${ }^{1}$ Department of Physical Education and Sports, University of Granada, Granada; ${ }^{2}$ Department of Physical Education, University of Cádiz, Cádiz; ${ }^{3}$ Department of Physiology, University of Granada, Granada, Spain

Background: Since fibromyalgia is a complex widespread pain condition with large impact on physical and psychological health, ${ }^{1}$ it is imperative to focus on modifiable factors that might decrease the impact of the disease on patients' lives. Accordingly, obesity and cardiorespiratory fitness (CRF) have been proposed as possible targets related to lower fibromyalgia severity and tenderness. ${ }^{2,} 3$ However, based on the Fat but Fit Paradigm $\left[,{ }^{4}\right.$ no previous studies have examined if women with adverse body mass index (BMI) but high CRF, might present lower fibromyalgia severity and tenderness than those with non-adverse BMI and low CRF.

Objectives: To examine the combined association of BMI and CRF with fibromyalgia severity and tenderness in women with fibromyalgia.

Methods: A total of 433 women with fibromyalgia $(51.8 \pm 7.5$ years old) were included in this cross-sectional study. BMI was calculated and CRF was assessed with the 6 min walk test (6-MWT). The fibromyalgia severity and its components (function, overall impact and symptom severity) along with tenderness were assessed with the Revised Fibromyalgia Impact Questionnaire (FIQR) and algometry, respectively. BMI groups were stratified according to international criteria.
Fit and unfit cut-offs were established according to the median value (fit $\geq 489 \mathrm{~m}$, unfit $<489 \mathrm{~m}$ in the 6-MWT). Analyses of covariance and Bonferroni post-hoc analyses were used to assess the combined association of BMI and CRF with FIQR variables and tenderness, and the differences of these outcomes variables between the groups created from the combination of the different levels of BM and CRF, respectively. The potential confounders were age, occupational status, medication for relaxing or sleeping, and antidepressants.

Results: Normal-weight and fit women showed better function, and lower overal impact and fibromyalgia severity than obese and unfit women (all, $\mathrm{p} \leq 0.05$ ). Overweight but fit women showed better function, and lower overall impact and fibromyalgia severity than normal-weight and unfit women (all, $p<0.01$ ) or obese and unfit women (all, $p<0.001$ ). Additionally, overweight but fit women showed lowe symptom severity than obese and unfit women $(p<0.001)$. Obese but fit women experienced lower tenderness than normal-weight and unfit women $(p=0.038)$ For the remaining analyses, differences of outcomes variables between groups were not statistically significant $(p>0.05)$.

Conclusions: The combination of BMI and CRF was significantly associated with the fibromyalgia severity and tenderness. Since overweight and obese fit women showed lower fibromyalgia severity and tenderness, it seems that the "Fat but Fit" paradigm might play an important role on fibromyalgia. These findings suggest that fitness might be able to counteract the adverse influence of obesity on fibro myalgia severity and tenderness. However, future physical exercise and dietary interventions are warranted to ascertain these findings.

\section{REFERENCES:}

[1] Segura-Jimenez V, et al. Semin Arthritis Rheum 2015 Apr;44(5):563-570.

[2] Segura-Jimenez V, et al. Eur J Pain 2016 May;20(5):811-821.

[3] Soriano-Maldonado A, et al. Arthritis Care Res. 2015 Nov;67(11):15611570

[4] Ortega FB, et al. CircRes 2016 May;118(11):1752-1770.

Disclosure of Interest: None declared

DOI: 10.1136/annrheumdis-2018-eular.6389

\section{THU0515 SOMATOSENSORY TEMPORAL DISCRIMINATION IS IMPAIRED IN FIBROMYALGIA}

Z. Gunendi ${ }^{1}$, M. Polat ${ }^{2}$, D. Vurallı ${ }^{3}$, B. Cengiz ${ }^{3} .{ }^{1}$ Physical Medicine and Rehabilitation, Division of Rheumatology; ${ }^{2}$ Physical Medicine and Rehabilitation; ${ }^{3}$ Gazi University Faculty of Medicine, Ankara, Turkey

Background: Fibromyalgia is the prototypical central sensitivity syndrome which is associated with increased sensitivity to pain and other stimuli. Somatosensory temporal discrimination (STD) is the perception of two discrete stimuli applied at short intervals as separate. The evaluation of STD ability essentially provides information about central processing of sensory stimuli. ${ }^{1}$

Objectives: In this study, we aimed to evaluate whether STD ability, which requires an intact central sensory processing, is altered in patients with fibromyalgia.

Methods: Fifteen patients with fibromyalgia and 15 healthy subjects participated in the study. Demographic characteristics of participants and severity for fatigue sleep quality, cognitive symptoms, somatic symptoms and health-related quality of life in fibromyalgia patients were recorded. STD thresholds were measured from the dorsum of the dominant hands of the participants by using a constant current stimulator ${ }^{2}$

Results: Patients with fibromyalgia had higher STD thresholds than healthy subjects (table 1). There were significant correlations between STD thresholds and pain intensity, fibromyalgia impact questionnaire scores and symptom severity scale scores in fibromyalgia group $(p=0.006, r=0.68 ; p=0.037, r=0.54 ; p=0.017$ $r=0.61$ respectively).

Table 1 STDT measures and clinical characteristics of study participants

\begin{tabular}{lcccc}
\hline & $\begin{array}{c}\text { Fibromyalgia group }(\mathrm{n}: 15) \\
\text { mean } \pm \text { SD }\end{array}$ & $\begin{array}{c}\text { Control group }(\mathrm{n}: 15) \\
\text { mean } \pm \mathrm{SD}\end{array}$ & $\begin{array}{c}\text { Mean } \\
\text { difference } \\
(95 \% \mathrm{Cl})\end{array}$ & $p$ \\
\hline Pain (VAS), & $7.3 \pm 1.1$ & & & \\
$\mathrm{~cm}$ & $58.8 \pm 5.5$ & & & \\
FIQ score & $7.7 \pm 1.4$ & $33.4 \pm 4.6$ & $35.7(30.6-$ & $<0.001$ \\
SSSS & $69.1 \pm 8.6$ & & $40.8)$ & \\
STDT, ms & & & & \\
\end{tabular}

VAS: Visual analogue scale, FIQ: Fibromyalgia impact questionnaire, SSSS Symptom severity scale score, STDT: Somatosensory temporal discrimination threshold, SD: Standard deviation, Cl: Confidence interval

Conclusions: Somatosensory temporal discrimination ability is impaired in fibromyalgia patients compared to healthy subjects. Disrupted somatosensory temporal discrimination ability correlates with increased widespread pain and severity of 
other symptoms including fatigue, sleep quality, cognitive symptoms, somatic symptoms and decreased functional status. The impaired somatosensory temporal discrimination ability indicates an alteration in higher cognitive sensory processing in fibromyalgia.

\section{REFERENCES:}

[1] Vuralli D, Boran HE, Cengiz B, Coskun O, Bolay H. Somatosensory temporal discrimination remains intact in tension-type headache whereas it is disrupted in migraine attacks. Cephalalgia 2017 Nov;37(13):1241-1247.

[2] Conte A, Modugno N, Lena F, Dispenza S, Gandolfi B, lezzi E, Fabbrini $G$, Berardelli A. Subthalamic nucleus stimulation and somatosensory temporal discrimination in Parkinson's disease. Brain 2010 Sep;133(9):265663.

Disclosure of Interest: None declared

DOI: 10.1136/annrheumdis-2018-eular.2760

\section{THU0516 EFFICACY AND SAFETY OF VITAMIN D3 IN PATIENTS WITH FIBROMYALGIA. RANDOMISED, DOUBLE BLIND, PLACEBO-CONTROLLED TRIAL}

L.I. Lozano Plata ${ }^{1}$, M.A. Garza Elizondo ${ }^{1}$, D. Vega Morales ${ }^{1}$, J.A. Esquivel Valerio $^{1}$, D.A. Galarza Delgado ${ }^{1}$, K. Silva Luna ${ }^{1}$, R. Díaz Niño de Rivera ${ }^{2}$ A. Garza Guerra ${ }^{2}$, G. Serna Peña ${ }^{1}$, I. Hernández Galarza ${ }^{1}$, L.E. Ramírez Monterrubio ${ }^{1}$, J.P. Carrizales Luna ${ }^{1} .{ }^{1}$ Rheumatology Service; ${ }^{2}$ Psychiatry Service, Universidad Autónoma de Nuevo León, Monterrey, Mexico

Background: fibromyalgia (FM) is a disease characterised by widespread pain, sometimes fatigue, memory problems and sleep disturbances. It has been suggested that low blood levels of vitamin D correlate with increased pain scores in patients with FM. A recent meta-analysis indicated that vitamin D may decrease pain scores in patients with FM, but with a low quality trials.

Objectives: to assess the efficacy and safety of vitamin D3 in Fibromyalgia patients.

Methods: a 12 week randomised, double blind, placebo-controlled trial in eighty FM patients according to the criteria of the American College of Rheumatology (ACR) 2010 who were randomised into two groups, the treatment group $(n=40)$ received 50,000 IU of oral vitamin D3 weekly, the second group $(n=40)$ received placebo for 12 weeks. The primary outcome was to assess the change in the Spanish version of Fibromyalgia Impact Questionnaire (S-FIQ) and Visual Analogue Scale (VAS 0-10) from baseline to week 12. Baseline serum calcium levels were measured in all subjects. Vitamin D levels were measured by chemiluminescence considering normal ranges between 30 and $100 \mathrm{ng} / \mathrm{ml}$, insufficiency between 10 and $30 \mathrm{ng} / \mathrm{ml}$ and deficiency less than $10 \mathrm{ng} / \mathrm{ml}$, baseline and after 12 weeks.

Results: of the total, $61 / 80(76 \%)$ had vitamin D insufficiency, $8 / 80(10 \%)$ deficiency and $11 / 80(14 \%)$ normal levels, the mean overall level of vitamin D was $21.2 \pm 9.0$. There was no statistically significant reduction in S-FIQ scores in patients in the treatment group compared with placebo $(47.0 \pm 23.3$ vs $43.9 \pm 25.0$, $\mathrm{p}=0.56$ ) after 12 weeks; there was also no statistically significant decrease in VAS scores $(6 \pm 5$ vs $4 \pm 4.5, p=0.57)$. There was no improvement in the perception of pain when normalising vitamin $D$ levels. No serious adverse events were reported in both groups.

Table 1 Baseline characteristics:

\begin{tabular}{lccc}
\hline & $\begin{array}{c}\text { Treatment } \\
(\mathrm{n}=40)\end{array}$ & Placebo $(\mathrm{n}=40)$ & $\mathrm{p}$ \\
\hline Age, mean (SD), years & $50.3(11.9)$ & $51.4(9.5)$ & 0.6 \\
BMI median (IQR) & $26.8(7.3)$ & $27.2(5.29)$ & 0.7 \\
Primary FM n (\%) & $18(48.6)$ & $19(51.4)$ & 0.8 \\
Secondary FM n (\%) & $22(51.2)$ & $21(48.8)$ & 0.8 \\
Tender Points median (IQR) & $12.5(4.4)$ & $14(7)$ & 0.2 \\
Basal Vitamin D median (IQR) & $20.1(14.5)$ & $12.6(13.4)$ & 0.2 \\
Vitamin D (\%) & & & 0.24 \\
Normal & $7(17.5)$ & $4(10)$ & \\
Insuficiency & $31(77.5)$ & $30(75)$ & \\
Deficiency & $2(5)$ & $6(15)$ & 0.48 \\
Baseline FIQ mean (SD) & $64.51(15.25)$ & $61.88(18.21)$ & 0.36 \\
Baseline VAS median (IQR) & $6(3)$ & $6(3.5)$ & \\
Primary outcomes & & & 0.56 \\
Final FIQ mean (SD) & $47.09(23.37)$ & $43.9(25.02)$ & 0.57 \\
Final VAS median (IQR) & $6(5)$ & $4(4.5)$ & 0.59 \\
Delta FIQ median (IQR) & $-16.39(35.28)$ & -18.94 & \\
& & $(105.13)$ & 0.0001 \\
Control Vitamin D median & $50.8(24.9)$ & $20.7(5.84)$ & \\
(IQR) & & &
\end{tabular}

Conclusions: at 12 weeks of treatment with vitamin D3 50,000 IU versus placebo in patients with fibromyalgia had no statistically significant differences in the FIQ and VAS. It may be possible to find greater benefit from vitamin D if this period is extended.
REFERENCES:

[1] Clauw DJ. Fibromyalgia: a clinical review. JAMA 2014; 311(15):15471555.

[2] Yong WC, Sanguankeo A, Upala S. Effect of vitamin D supplementation in chronic widespread pain: a systematic review and meta-analysis. Clin Rheumatol 2017 Dec;36(12):2825-2833.

Disclosure of Interest: None declared

DOI: 10.1136/annrheumdis-2018-eular.6541

\section{THU0517 IDENTIFICATION OF CANDIDATE GENES ASSOCIATED WITH FIBROMYALGIA SUSCEPTIBILITY IN SOUTHERN SPANISH WOMEN: THE AL-ÁNDALUS PROJECT}

F. Estevez-Lopez ${ }^{1,2}$, D. Camiletti-Moirón³ ${ }^{3}$, V.A. Aparicio ${ }^{1}$, V. Segura-Jiménez ${ }^{3}$, I. C. Álvarez-Gallardo ${ }^{3}$, A. Soriano-Maldonado ${ }^{4}$, M. Borges-Cosic ${ }^{1}$, P. AcostaManzano $^{1}$, R. Geenen², M. Delgado-Fernández ${ }^{1}$, L.J. Martínez-González ${ }^{5}$, J. R. Ruiz ${ }^{1}$, M.J. Álvarez-Cubero ${ }^{5} .{ }^{1}$ University of Granada, Granada, Spain; ${ }^{2}$ Utrecht University, Utrecht, Netherlands; ${ }^{3}$ University of Cádiz, Cádiz; ${ }^{4}$ University of Almería, Almería; ${ }^{5}$ GENyO, University of Granada, Granada, Spain

Background: Family aggregation suggests genetic susceptibility to fibromyalgia. ${ }^{1}$ Candidate-gene studies on fibromyalgia susceptibility often include a small number of SNPs, ${ }^{2,3}$ which is a limitation. ${ }^{4}$ Additionally, there is a paucity of evidence in Europe.

Objectives: To compare genotype frequencies of candidate single nucleotide polymorphisms (SNPs) in a well-characterised sample of Spanish women with fibromyalgia and healthy non-fibromyalgia women.

Methods: Three hundred and fourteen women with a diagnosis of fibromyalgia (cases) and 112 non-fibromyalgia healthy (controls) women participated in the present candidate-gene study. Buccal swabs were collected for DNA extraction. Using TaqMan OpenArray, we analysed 63 single nucleotide polymorphisms (SNPs) of 33 genes related to fibromyalgia susceptibility, symptoms, or potential mechanisms.

Results: The rs841 and rs1799971 GG genotype was more frequently observed in fibromyalgia than in controls ( $p=0.04$ and $p=0.02$, respectively). The rs2097903 AT/TT genotypes were also more often present in the fibromyalgia participants than in their control peers $(\mathrm{p}=0.04)$.

Conclusions: We identified, for the first time, associations of the rs841 (guanosine triphosphate cyclohydrolase 1 gene) and rs2097903 (catechol-O-methyltransferase gene) SNPs with higher risk of fibromyalgia susceptibility. We also confirmed that the rs 1799971 SNP (opioid receptor $\mu 1$ gene) might confer genetic risk of fibromyalgia. Further studies are needed to confirm or refute the present findings.

\section{REFERENCES:}

[1] Arnold LM, et al. Arthritis Rheum 2004;50(3):944-52.

[2] Lee YH, et al. Rheumatol Int 2012;32(2):417-26.

[3] Estévez-López F, et al. Rheumatol Int (in press). doi:10.1007/s00296-0173896-x

[4] Klepstad P. Scand J Pain 2014;5:8-9.

Acknowledgements: The authors report no conflicts of interest. This work was supported by the Spanish Ministry of Economy and Competitiveness [ $+\mathrm{D}_{+}$ DEP2010-15639, I+D+ i DEP2013-40908 R, BES-2014-0 67 612]; the Spanish Ministry of Education [FPU2014/02518]

Disclosure of Interest: None declared

DOI: 10.1136/annrheumdis-2018-eular.6513

\section{THU0518 THE DIAGNOSTIC VALUE OF SELECTED MICRORNAS IN PATIENTS WITH FIBROMYALGIA ASSOCIATED WITH RHEUMATOID ARTHRITIS: A PILOT STUDY}

L.J. Ghib ${ }^{1}$, R. Cojocneanu-Petric ${ }^{2}$, L. Budisan², L. Muntean ${ }^{1}$, I. Filipescuㄹ, I. Berindan-Neagoe ${ }^{2}$, S. Rednic ${ }^{1} .{ }^{1}$ Rheumatology Department, ${ }^{2}$ Research Center for Functional Genomics and Translational Medicine, "Iuliu Hatieganu" University of Medicine and Pharmacy, Cluj Napoca, Romania

Background: Fibromyalgia (FM) is present in a significant proportion of patients with rheumatoid arthritis (RA) ${ }^{1}$. Diagnosis and management of patients with rheumatoid arthritis and associated fibromyalgia (FRA) is challenging ${ }^{1}$. MicroRNAs (miRNA) are small nonconding RNAs that target mRNA and repress protein production. Recent studies have identified specific patterns of microRNA (miRNA) expression in FM patients ${ }^{3}$.

Objectives: Our objectives were to determine if there are differences in expression levels of miR let-7a, miR-21-5 p, miR -143 and miR-103a-3p in the blood of 